\title{
Overexpression of serine racemase in retina and overproduction of D-serine in eyes of streptozotocin-induced diabetic retinopathy
}

\author{
Haiyan Jiang ${ }^{1,2}$, Junxu Fang ${ }^{1,2}$, Bo Wu ${ }^{3}$, Guibin Yin ${ }^{1,2}$, Lin Sun ${ }^{1,2}$, Jia Qu ${ }^{1,2}$, Steven W Barger ${ }^{4,5}$ and \\ Shengzhou $\mathrm{Wu}^{1,2^{*}}$
}

\begin{abstract}
Background: Recent data indicate that inflammatory mechanisms contribute to diabetic retinopathy (DR). We have determined that serine racemase (SR) expression is increased by inflammatory stimuli including liposaccharide (LPS), amyloid $\beta$-peptide (A-beta), and secreted amyloid precursor protein (SAPP); expression is decreased by the anti-inflammatory drug, dexamethasone. We tested possibility that SR and its product, D-serine, were altered in a rat model of DR.
\end{abstract}

Methods: Intraperitoneal injection of streptozotocin (STZ; $70 \mathrm{mg} / \mathrm{kg}$ body weight) to Sprague-Dawley rats produced type-I diabetic mellitus (fasting blood sugar higher than $300 \mathrm{mg} / \mathrm{dL}$ ). At 3 and 5 months after STZ or saline injection, retinas from some rats were subjected to cryosectioning for immunofluorescent analysis of SR and TUNEL assay of apoptosis. Retinal homogenates were used to detect SR levels and Jun N-terminal kinase (JNK) activation by immunoblotting. Aqueous humor and retina were also collected to assay for neurotransmitters, including glutamate and D-serine, by reverse-phase HPLC.

Results: Compared to saline-injected rats, STZ-injected (diabetic) rats showed elevation of SR protein levels in retinal homogenates, attributed to the inner nuclear layer (INL) by immunofluorescence. Aqueous humor fluid from STZ-injected rats contained significantly higher levels of glutamate and D-serine compared to controls; by contrast, D-serine levels in retinas did not differ. Levels of activated JNK were elevated in diabetic retinas compared to controls.

Conclusions: Increased expression of SR in retina and higher levels of glutamate and D-serine in aqueous humor of STZ-treated rats may result from activation of the JNK pathway in diabetic sequelae. Our data suggest that the inflammatory conditions that prevail during DR result in elevation of D-serine, a neurotransmitter contributing to glutamate toxicity, potentially exacerbating the death of retinal ganglion cells in this condition.

Keywords: diabetic retinopathy, inflammation, retinal ganglion cell, inner nuclear layer, glutamate

\section{Background}

Diabetic retinopathy (DR) is a sight-threatening complication of diabetic mellitus that becomes prevalent after about a decade with disease. The natural history of DR has been divided into an early, nonproliferative stage, and a later, proliferative stage. Multiple etiologic hypotheses have been proposed, including protein kinase

\footnotetext{
* Correspondence: wszlab@mail.eye.ac.cn

${ }^{1}$ School of Optometry and Ophthalmology and Eye Hospital, Wenzhou Medical College. 270 Xueyuan Road, Wenzhou, Zhejiang, 325003, P.R.China Full list of author information is available at the end of the article
}

C activation [1,2], excessive production of advanced glycation end products (AGEs) [3,4], and reactive oxygen species stemming from overconsumption of NAPDH as a result of overactivation of aldose reductase activity [5-7]. The pathology of DR involves microvasular changes, including blood-retinal barrier (BRB) breakdown, microaneurysm, increased expression of intercellular adhesion molecule 1 (ICAM-1), and death of endothelial cells and pericytes [8-11]. These microvascular changes frequently accompany inflammation. In addition to inflammation-related changes in retinal

\section{Biomed Central}


vessels, DR also involves neurodegeneration in the retinal ganglion cell layer (RGCL) and inner nuclear layer (INL) [12]; some evidence indicates this neuronal cell death precedes vascular changes in DR $[12,13]$. Excitotoxins including homocysteine and glutamate can induce toxicity in RGCs [14]; increased retinal glutamate is also found in the streptozotocin (STZ)-induced model of diabetes [15]. Recently, excitotoxicity contributing to neural degeneration was also linked to activity of serine racemase (SR), an enzyme that converts L-serine to its dextrarotatory enantiomer [16-19]. Whole-cell recording in rat retinas has indicated that $\mathrm{D}$-serine enhances currents transmitted by $\mathrm{N}$-methyl $\mathrm{D}$-aspartate (NMDA) receptors, and removal of $\mathrm{D}$-serine by $\mathrm{D}$-amino acid oxidase (DAAOx) returned the currents to control amplitudes [20].

SR has been widely studied in recent decades. In neural tissues, it was initially identified in protoplasmic astrocytes [21], then microglia [16], and later in Schwann cells [22]. Its product D-serine acts as an agonist at the glycine $_{B}$ site of the NMDA receptor and influences neurotransmission [20]. Shortages of D-serine in the CNS have been linked to schizophrenia [23]. Dserine administration has helped to reverse negative symptoms of schizophrenia in clinical trials of combinatorial treatment regimens [24], and a loss-of-function mutation in SR produces schizophrenia-related behaviors in mice [25]. Overproduction of D-serine has been associated with excitotoxicity in vitro [16], amyotrophic lateral sclerosis [26], and experimental epilepsy [27]. Targeted knockout of serine racemase protects against toxicity of amyloid $\beta$-peptide $(A \beta)$ and ischemic injury $[18,19]$.

Regulation of serine racemase occurs at transcriptional, translational, and post-translational levels. Phosphorylation of SR at Thr-71 increases SR activity [28], and inhibition of proteasome activity increases SR protein levels [29]. At the transcriptional level, inflammatory stimuli-including $A \beta$, lipopolysaccharide (LPS) [16], and secreted amyloid precursor protein (sAPP)increase SR mRNA [30]; and dexamethasone decreases SR mRNA [31]. Taken together, these lines of evidence suggest that inflammation regulates SR expression and thereby contributes to the etiology of DR. Therefore, we sought to determine whether production of SR and its product, D-serine, change in a model of DR utilizing the STZ-induced rat model of diabetes.

\section{Methods}

\section{Materials}

STZ was purchased from Sigma (St Louis, MO). Microsyringes and SR antibody were purchased from BD Biosciences (San Jose, CA). JNK, phospho-SAPK/JNK,
phospho-c-Jun (Ser73), and GAPDH antibodies were purchased from Cell Signaling Technology, Inc. (Danvers, MA). An antibody detecting von Willebrand Factor (vWF) was purchased from Abcam (Cambridge, MA). Glucometer, in situ cell death detection kits, and fluorescein were purchased from Roche Diagnostics (Germany). Hematoxylin and eosin (H\&E) were purchased from Beyotime Institute of Biotechnology (Beijing, China). CL-Xposure films were purchased from Thermo Scientific Branch (Shanghai, China). Pierce ECL Western Blotting Substrate was purchased from Thermo Scientific (Rockford, IL). Protease inhibitor cocktail was purchased from Calbiochem (San Diego, CA). Chloral hydrate, alcohol, and neutral balsam were purchased from Shanghai Pharmacy Company (Shanghai, China).

\section{Animals}

Sprague-Dawley rats were purchased from the Shanghai Animal Experimental Center, Chinese Academy of Sciences and housed in standard pathogen-free (SPF) animal facilities with automatic illumination on a 12-h cycle at Wenzhou Medical College. All experiments were approved by the Wenzhou Medical College Committee according to Association for Research in Vision and Ophthalmology (ARVO) regulations on the use and care of animals.

\section{Establishment of DR rat model}

Rats at 2 months of age were randomly assigned to groups receiving an intraperitoneal (i.p.) saline injection $(\mathrm{N}=15)$ or a single i.p. injection of STZ $(70 \mathrm{mg} / \mathrm{kg}$ body weight; $\mathrm{N}=25$ ). At the time of injection, the body weights within a given experimental group varied (249$281 \mathrm{~g}$ ), but the mean body weights were identical for the STZ and saline groups. Blood glucose levels were monitored with a glucometer once a week, and final measurements were recorded at the end of the experiment immediately prior to euthanasia. Rats exhibiting fasting glucose levels in excess of $300 \mathrm{mg} / \mathrm{dL}$ were designated diabetic rats; STZ-injected rats not reaching this criterion were excluded from the experiments.

\section{Collection of aqueous humor and retinas}

After anethesitizing rats with $10 \%$ chloral hydrate at 0.3 $\mathrm{mL} / 100$ g body weight, a microsyringe $(300 \mu \mathrm{l})$ was inserted at the edge of cornea, and $20 \mu \mathrm{l}$ of aqueous fluid was drawn from each eye. The rats were then euthanized, and the retinas were collected for analysis by immunoblotting or histology. Eyes were removed and opened by circumferential incision just below the ora serrata, and anterior segment and the vitreous were discarded. Under a dissection microscope, the retina was gently lifted off the eyecup. 


\section{H\&E staining}

Retinas were immersion-fixed in $4 \%$ formaldehyde, dehydrated through graded ethanol steps and xylene, then embedded in paraffin. Sections were cut with a vibrotome (Leica RM 2135) at a thickness of $5 \mu \mathrm{m}$ and mounted onto glass slides. The mounted sections were deparaffinized with xylene and rehydrated with graded ethanol steps from $100 \%$ to $70 \%$. Hematoxylin was used to stain the sections for $3 \mathrm{~min}$, followed by washing with tap water. After treatment with $0.1 \% \mathrm{HCl}$ and $0.1 \%$ $\mathrm{NH}_{4} \mathrm{OH}$, sections were exposed to eosin for $3 \mathrm{~min}$, then dehydrated with graded ethanol steps and xylene, and coverslipped in neutral balsam. Observations were made under phase-contrast and bright-field microscopy (Olympus BX 41).

\section{TUNEL staining}

Apoptosis was analyzed with the In Situ Cell Death Detection Kit (Roche). Frozen sections of the rat retinas were cut on a cryostat. The sections were postfixed with $4 \%$ paraformaldehyde and permeablized with $0.1 \%$ Triton $\mathrm{X}-100$. A $50-\mu \mathrm{l}$ TUNEL reaction mixture was added to each sample, and the slides were incubated in a humidified atmosphere for $60 \mathrm{~min}$ at $37^{\circ} \mathrm{C}$ in the dark and analyzed by fluorescence microscopy with an FITC filter.

\section{Western blotting for rat retinal homogenates}

Retinas were homogenized with protein lysis buffer containing protease inhibitor cocktail and then centrifuged at $13,000 \times \mathrm{g}$ at $4^{\circ} \mathrm{C}$ for $10 \mathrm{~min}$ to remove insoluable pellets. The supernatants were quantified with BCA reagents (Beyotime Biotechnology). Retinal proteins (50 "g) from control or STZ-injected rats were loaded in individual lanes, resolved with SDS-PAGE analysis $(12 \%)$, and then electrophoretically transferred to a nitrocellulose membrane. The transfer efficiency was monitored with Ponceau S (Sigma), and blots were blocked with 3\% BSA or skim milk. SR antibody (1:500) or JNK/phospho-JNK antibody (1:1000) was diluted in Tris-buffered saline ( $\mathrm{pH} 7.4$ ) with $0.1 \%$ Tween-20 supplement (TBS-T) and applied to the blots overnight at $4^{\circ} \mathrm{C}$. Following washes with TBS, a peroxidase-conjugated secondary antibody was applied at a dilution of 1:5000. Washes were followed by development with Pierce ECL Western Blotting Substrate. Each membrane probed for SR or JNK was stripped and probed for GAPDH detection.

\section{Immunofluorescence}

Frozen sections of retina were blocked with skimmed milk overnight. SR antibody (1:100) in PBS containing $0.1 \%$ Triton $\mathrm{X}-100$ was applied to the sections for $1 \mathrm{~h}$ at room temperature then overnight at $4^{\circ} \mathrm{C}$. On the following day, the samples were washed three times with PBS and incubated for $1 \mathrm{~h}$ at room temperature with a secondary antibody conjugated to Alex Fluor 488 (1:1000). Following incubation in secondary antibody, the sections were washed in PBS at $4^{\circ} \mathrm{C}$, coverslipped, and examined with a Zeiss Axiovert 200 equipped with epifluorescence optics. Images were recorded with a digital camera. Specificity was confirmed by omission of primary antibody.

\section{HPLC measurement of D-serine}

Detection of D-serine by reverse-phase HPLC was performed using methods similar to those of Hashimoto et al [32]. Vitreous humor or retinas were collected as described above. Vitreous fluid or retinal homogenates were precipitated with $10 \%$ trichloroacetic acid (TCA) and cleared by centrifugation. TCA was removed from the supernatants with water-saturated ether, and they were then derivatized with a 3:7 mixture of solution A $(30 \mathrm{mg} / \mathrm{ml} \mathrm{t}$-BOC-L-cysteine, $30 \mathrm{mg} / \mathrm{ml} o$-phthaldialdehyde in methanol): solution $B$ (100 mM sodium tetraborate solution, $\mathrm{pH}$ 9.4). A 3.5- $\mu$ ZORBAX Eclipse AAA column $(150 \times 4.6 \mathrm{~mm})$ was used to separate the amino acids. A linear gradient was established from $100 \%$ buffer A (0.1 M sodium acetate buffer, $\mathrm{pH} 6$; $7 \%$ acetonitrile; $3 \%$ tetrahydrofuran) to $100 \%$ buffer B $(0.1 \mathrm{M}$ sodium acetate buffer, $\mathrm{pH} 6 ; 4 \%$ acetonitrile; $3 \%$ tetrahydrofuran) over $60 \mathrm{~min}$ at $0.8 \mathrm{ml} / \mathrm{min}$. Fluorescence was monitored with $344 \mathrm{nM}$ excitation and $443 \mathrm{nM}$ emission. In addition to their consistent retention times, Dserine peaks were confirmed by sensitivity to D-amino acid oxidase (DAAOx) digestion.

\section{Statistics}

Pairwise comparisons between diabetic and control rats were assessed using Student's t-test. $\mathrm{P} \leq 0.05$ was accepted as indicative of a significant difference.

\section{Results}

\section{Establishment of DR rat model}

To examine the metabolic status of DR rats, we monitored fasting blood glucose once per week and body weights (BW) before and after STZ injection. The parameters for these experimental rats are summarized in Table 1.

A previous study demonstrated RGC loss occurs in DR model [33]. We examined RGCL integrity in our rat subjects with H\&E and TUNEL staining. H\&E staining indicated a reduction in the number of RGCs in some areas of RGCL in diabetic rats 3 months after STZ injection, as compared to the saline-injected group (Figure 1, A vs. 1B); similar effects were observed at 5 months after STZ injection (not shown). The INL in the diabetic group was thinner than that in the salineinjected group (Figure 1B). Positive TUNEL staining was 
Table 1 Weight change and fasting blood sugar of AMC and diabetic rats

\begin{tabular}{|c|c|c|}
\hline $\begin{array}{c}\text { Ages of rats (months) } \\
\text { (months after manipulation) }\end{array}$ & $\begin{array}{l}\text { Weight (g) } \\
\text { Mean } \pm \text { SEM }\end{array}$ & $\begin{array}{c}\text { Fasting Blood Sugar } \\
\text { (mg/dL) } \\
\text { Mean } \pm \text { SEM }\end{array}$ \\
\hline $\begin{array}{c}2 \\
(0, \text { no treatment })\end{array}$ & $264.13 \pm 4.26$ & $105.98 \pm 2.67$ \\
\hline $\begin{array}{c}5 \\
\text { (3 mo. after saline) }\end{array}$ & $599.25 \pm 13.00$ & $102.17 \pm 2.79$ \\
\hline $\begin{array}{c}5 \\
\text { (3 mo. after STZ) } \\
\end{array}$ & $222.13 \pm 16.7 *$ & $451.13 \pm 11.61 *$ \\
\hline $\begin{array}{c}7 \\
\text { (5 mo. after saline) }\end{array}$ & $752.50 \pm 26.58$ & $103.05 \pm 4.49$ \\
\hline $\begin{array}{c}7 \\
\text { (5 mo. after STZ) }\end{array}$ & $247.80 \pm 5.25 *$ & $460.44+18.73 *$ \\
\hline
\end{tabular}

found localized to the RGCL and INL in retinas of DR rats (Figure 1D), whereas no staining was detected in retinas of saline controls (Figure 1C).

\section{Increased SR expression in retinas of STZ-induced DR model}

Previous studies have indicated that RGC death in DR may be associated with excitotoxicity $[14,34]$. Recent reports have indicated that $\mathrm{D}$-serine can contribute to excitotoxicity $[16-19,26]$. Therefore, we tested whether SR or its product D-serine increases in eyes during STZinduced DR. Retinas from DR and control rats were analyzed for SR expression, which was increased in DR

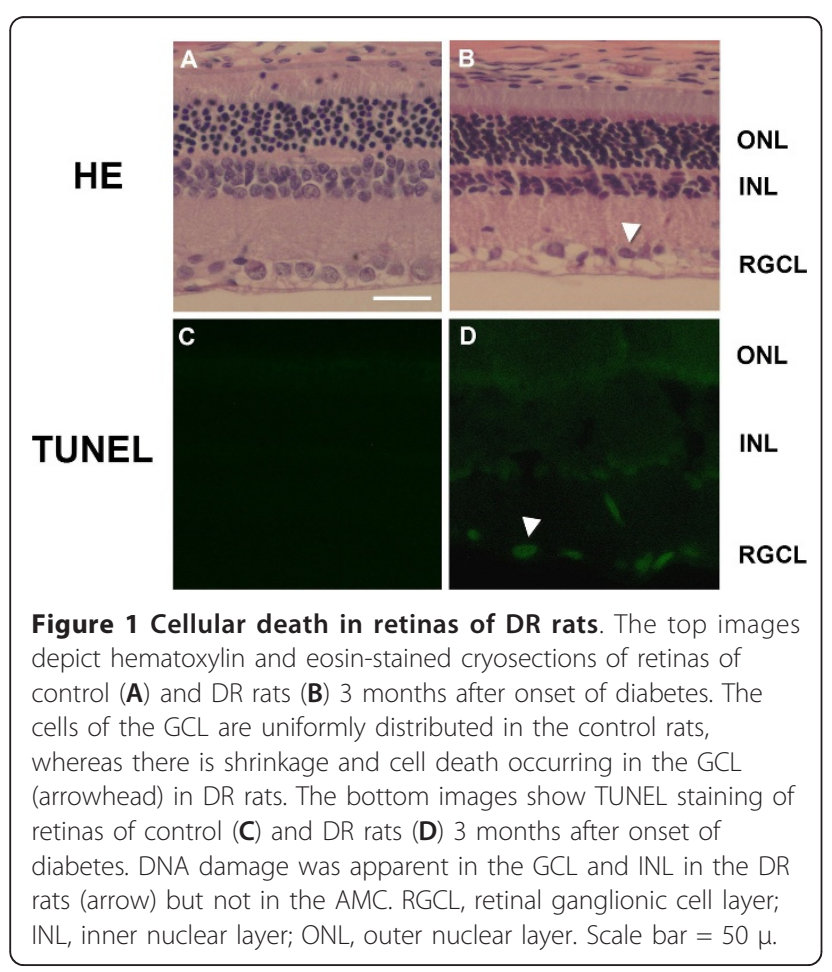

compared to controls at 3 and 5 months post-STZ injection (Figure 2). To determine whether this increased expression may be attributable to the retinal layer, immunofluorescence was performed on cryosections. The results indicate that the increased staining was localized mostly in the INL at 3 and 5 months post-STZ injection (Figure 3C, G) compared to controls (Figure 3A, E).

\section{Increased D-serine and glutamate in aqueous humor of DR rats}

Because levels of SR were found to be elevated in retinas, we next examined whether this translated into an increase in D-serine levels. Levels of D-serine showed a trend toward somewhat higher levels in diabetic rat retina 3 months after STZ, but there was not a significant difference at either time point. The RGC population may be vulnerable to excitotoxins that exist in ocular humor, levels of which would not be detected in assays of neural retina homogenates. We tested D-serine and glutamate in aqueous humor and found significant elevations of both of these excitatory amino acids in DR rats (Figure 4). We also attempted to assay D-serine in vitreous humor but the lens of the DR rats adhered to the retina so that the vitreous humor of DR rats was not easily isolated.

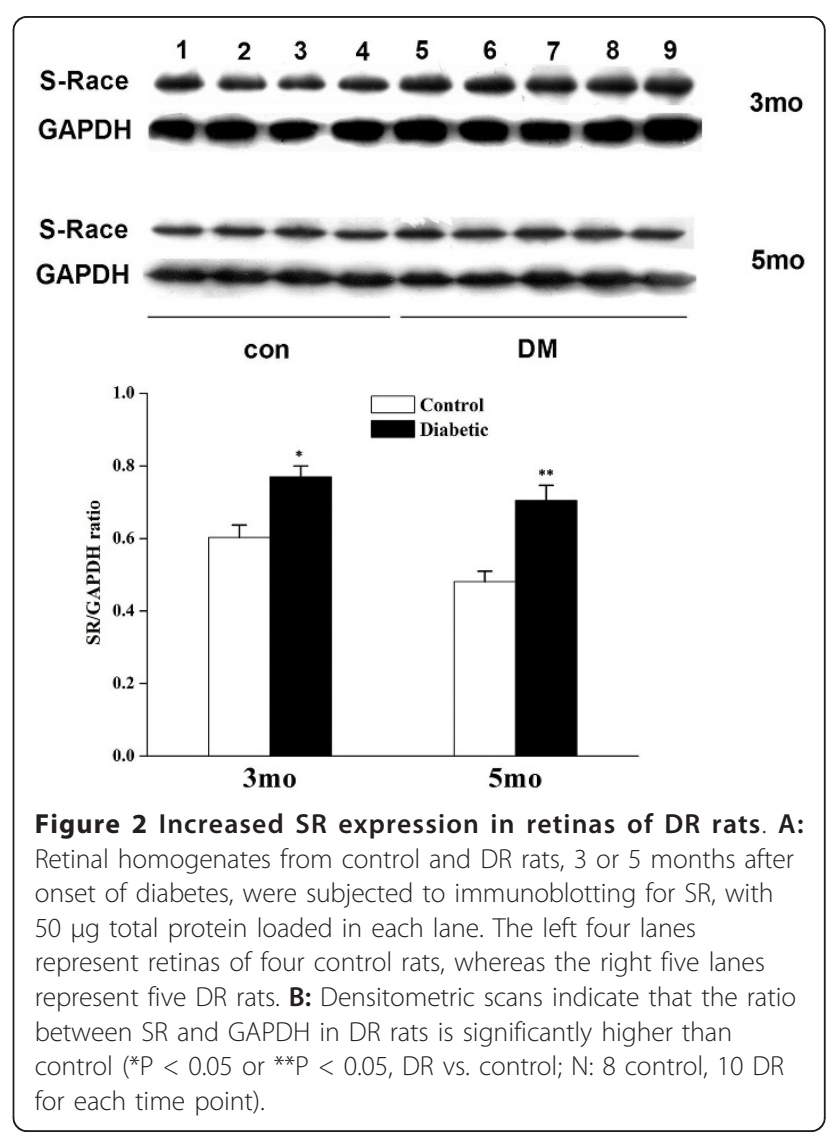



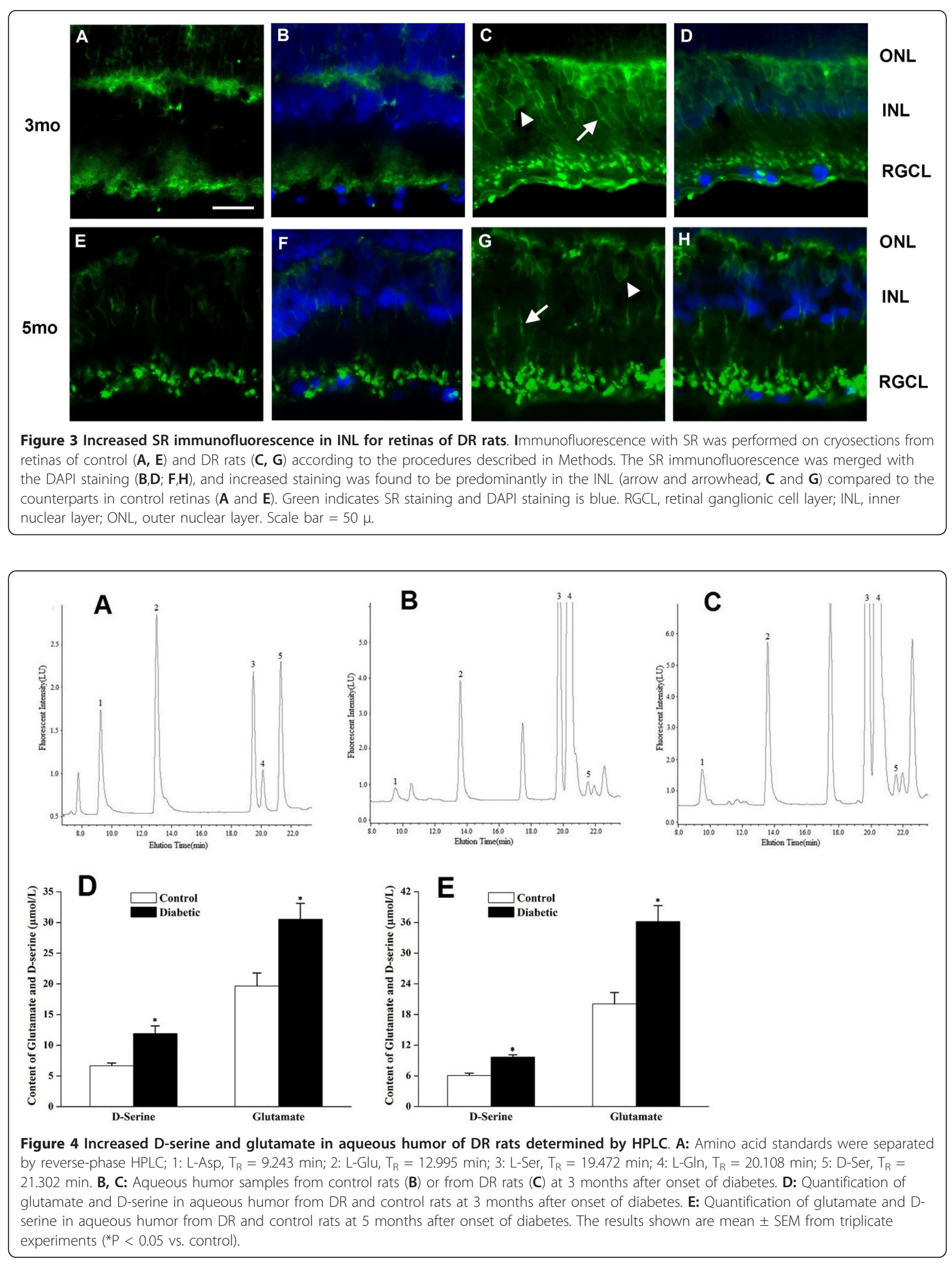
Increased phospho-JNK in retinas of DR

Previous reports indicate that the JNK pathway is activated in diabetes mellitus [35,36], and JNK activity is increased in DR [37]. We have demonstrated that inflammation increases SR expression in microglial cells via activation of the JNK pathway, which culminates in binding of a c-Fos/JunB transcription-factor complex to an AP-1 site in the SR intron 1c [31]. Therefore, we tested whether JNK contributes to increased SR expression in DR by assaying relative levels of phospho-JNK (54 and $46 \mathrm{kDa}$ ) in retinal homogenates. Compared with control, increased phospho-JNK was detected in DR homogenates at 3 or 5 months after onset of diabetes (Figure 5). By contrast, no increase in total JNK was detected, suggesting activation of extant kinase.

\section{Discussion}

Our results indicate that SR is elevated in retina and Dserine is increased in aqueous humor in the STZinduced model of DR. The increased SR expression in retina may result from activation of the JNK pathway in DR. To our knowledge, this is the first report of an increase in the levels of SR and D-serine in DR. We also found that glutamate levels in DR retina are $\sim 1.5$-fold higher than control, consistent with a report by Lieth et al. that glutamate is $\sim 1.6$-fold higher in DR retina [15].

We found that levels of total $\mathrm{D}$-serine in retina are 100-fold lower than those of glutamate (not shown); but this is consistent with their relative total concentrations in other neural tissues, reflecting the distinctions in compartmentalization and metabolic roles for these two amino acids. There were no significant differences in retinal D-serine between DR rats and controls, which may result from spillover of excess retinal D-serine into the ocular humors. Compared to those in adult retina, levels of D-serine were easily detected by reverse-phase HPLC in aqueous humor of adult rats, where D-serine levels were only one fifth those of glutamate. We also noticed that SR or D-serine were higher at 3 months after onset of diabetes than at 5 months after onset of diabetes. Possible explanations include the previously reported decline in SR expression with aging [38].

Increased SR expression in retina was positively correlated with JNK pathway activation, indicated by

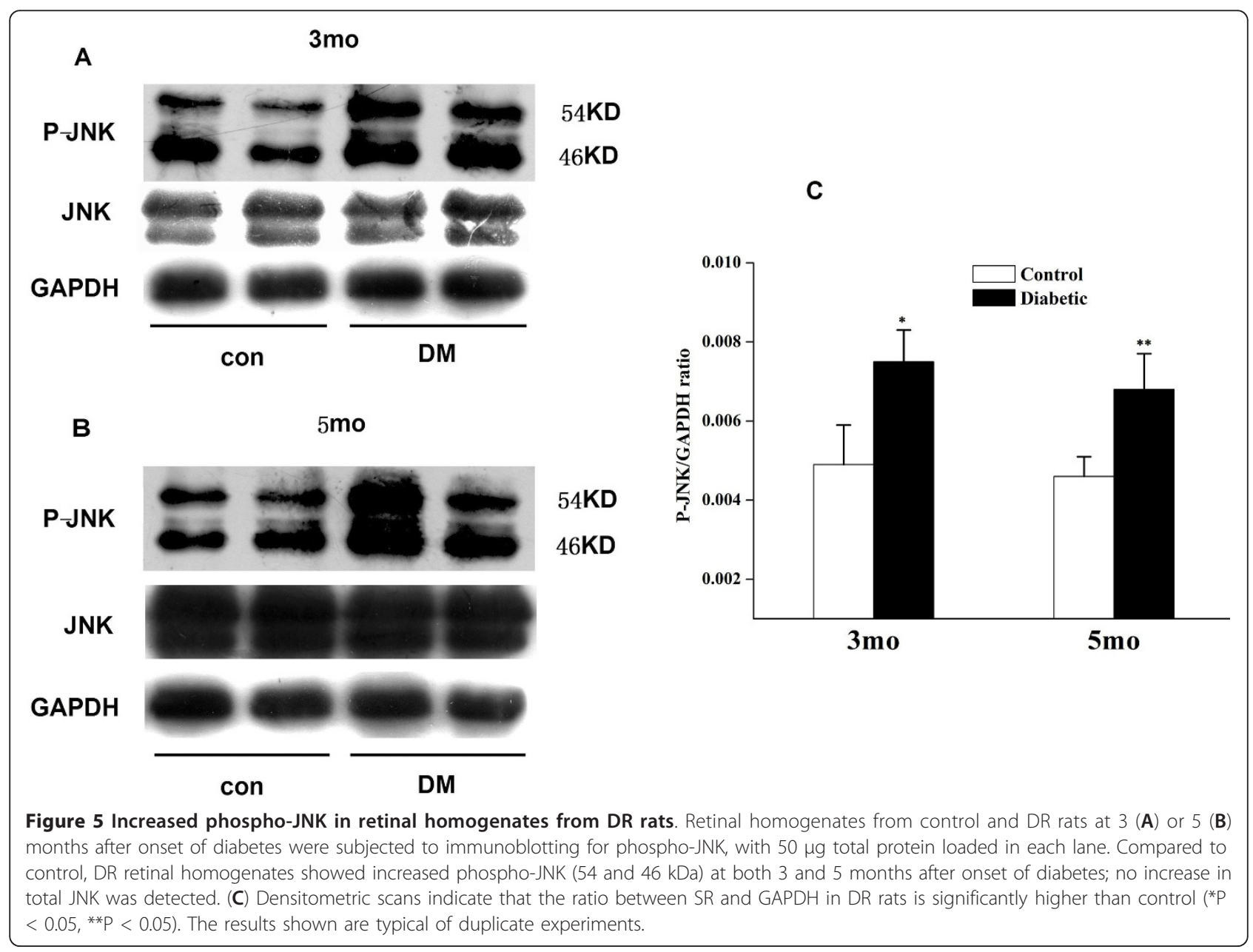


increased levels of phospho-JNK. Currently, we do not know which isoforms of JNK regulate SR expression in DR retina. JNK1 and JNK2 are found in all cells and tissues and their functions are redundant, and JNK3 is mostly localized in brain [39]. Thus, it seems likely that JNK1 or JNK2 is responsible for regulating SR expression by inflammation in DR retina. We previously demonstrated that downstream of JNK, a c-Fos/JunB complex is responsible for regulating SR expression by inflammatory stimuli in microglia [31]. In DR retina, we did detect increased phospho-JNK but not increased phospho-c-Jun or JunD. Potential changes in phosphoJunB in DR retina will be investigated in future studies.

In our study, increased SR was found primarily in INL. Judging from morphology, these are glial cells containing strong SR staining. These may include Müller cells, astrocytes, or other glial cells in retina expressing SR $[20,38,40]$. Retinal homogenates also contained an SR dimer resistent to the denaturation conditions of SDS-PAGE, as we previously documented for microglia [16], though in much smaller amounts than monomers (not shown).

Previous results have indicated that intravitreal injection of D-serine or glycine can enhance NMDA toxicity towards RGCs, whereas blocking the glycine ${ }_{B}$ binding site with 5,7-dichlorokynurenic acid (DCKA) or blocking glycine transport reduces toxicity [41]. Our results indicate increased levels of glutamate and D-serine in aqueous humor of DR rats and increased glutamate in retina as well; the increased glutamate in DR is consistent with another prior report [15]. Taken together, our data indicate that increased D-serine in the enclosed environment of eyes may exacerbate glutamate toxicity towards RGCs in DR.

Our results also indicated that vWF staining does not overlap with TUNEL staining (not shown), which suggests that endothelial cell death is not substantial at 3 or 5 months post-STZ injection. Previous reports have indicated that breakdown of the blood-retinal barrier (BRB) is limited, if not altogether absent, at early stages of STZ-induced DR $[42,43]$. These results suggest that leakage of leukocytes or their products due to BRB breakdown do not make a substantial contribution to RGC death. Nevertheless, leukocytes can extravasate through endothelial barriers, even in healthy vessels [44]. Once there, they may become activated by AGEs, molecules which could also contribute directly to neurodegenerative events $[45,46]$. In addition, blood-borne leukocytes or activation of resident glia can compromise neuronal function and viability via oxidative stresses, release of proteases, and the pathological production of prostanoids [47]. However, our work demonstrates that elevations in glutamate and D-serine may contribute to these inflammatory sequelae occurring in DR.

\section{Abbreviations}

SR: serine racemase; STZ: streptozotocin; DR: diabetic retinopathy; HPLC: high-pressure liquid chromatography.

\section{Acknowledgements}

Supported by Zhejiang Province Natural Science foundation (Y2110086), by start-up funding (89210001) from Wenzhou Medical College to Dr. Shengzhou Wu, and by NIH funds to Dr. Barger (P01AG012411).

\section{Author details}

${ }^{1}$ School of Optometry and Ophthalmology and Eye Hospital, Wenzhou Medical College. 270 Xueyuan Road, Wenzhou, Zhejiang, 325003, P.R.China. ${ }^{2}$ State Key Laboratory Cultivation Base and Key Laboratory of Vision Science, Ministry of Health, P.R.China and Zhejiang Provincial Key Laboratory of Ophthalmology and Optometry. 270 Xueyuan Road, Wenzhou, Zhejiang, 325003, P.R.China. ${ }^{3}$ Laboratory Animal Center, Wenzhou Medical College, 325035, Zhejiang, P.R.China. ${ }^{4}$ Department of Geriatrics, University of Arkansas for Medical Sciences, Little Rock, AR, 72205, USA. ${ }^{5}$ Geriatric Research Education and Clinical Center, Central Arkansas Veterans Healthcare System, Little Rock AR, 72205, USA.

\section{Authors' contributions}

Author $1(\mathrm{H}-\mathrm{Y} J)$ established the DR rat model and performed western blotting, immunofluorescence, H\&E staining, TUNEL assays, and HPLC measurements. Author 2 (J-XF) contributed to western blotting. Author 3 (BW) helped establish the DR rat model. Author 4 (G-BY) performed western blotting for phospho-JNK and phospho-c-Jun. Author 5 (LS) performed immunofluorescence for vWF. Author $6(J \mathrm{Q})$ provided expert opinions on the project. Author 7 (SWB) provided expert opinions on the project and contributed to writing of the manuscript, as well. Author 8 (S-ZW) conceived of this study, participated in its design and coordination, and wrote the manuscript. All authors read and approved the final manuscript.

\section{Competing interests}

The authors declare that they have no competing interests.

Received: 13 July 2011 Accepted: 22 September 2011

Published: 22 September 2011

\section{References}

1. Ishii H, Jirousek MR, Koya D, Takagi C, Xia P, Clermont A, Bursell SE, Kern TS, Ballas LM, Heath WF, et al: Amelioration of vascular dysfunctions in diabetic rats by an oral PKC beta inhibitor. Science 1996, 272:728-731.

2. Koya D, King GL: Protein kinase $C$ activation and the development of diabetic complications. Diabetes 1998, 47:859-866.

3. Giardino I, Edelstein D, Brownlee M: Nonenzymatic glycosylation in vitro and in bovine endothelial cells alters basic fibroblast growth factor activity. A model for intracellular glycosylation in diabetes. J Clin Invest 1994, 94:110-117.

4. Abdel-Wahab YH, O'Harte FP, Ratcliff $\mathrm{H}, \mathrm{McClenaghan} \mathrm{NH}$, Barnett $\mathrm{CR}$, Flatt PR: Glycation of insulin in the islets of Langerhans of normal and diabetic animals. Diabetes 1996, 45:1489-1496.

5. Van den Enden MK, Nyengaard JR, Ostrow E, Burgan JH, Williamson JR: Elevated glucose levels increase retinal glycolysis and sorbitol pathway metabolism. Implications for diabetic retinopathy. Invest Ophthalmol Vis Sci 1995, 36:1675-1685.

6. Leal EC, Santiago AR, Ambrosio AF: Old and new drug targets in diabetic retinopathy: from biochemical changes to inflammation and neurodegeneration. Curr Drug Targets CNS Neurol Disord 2005, 4:421-434.

7. Williamson JR, Chang K, Frangos M, Hasan KS, Ido Y, Kawamura T, Nyengaard JR, van den Enden M, Kilo C, Tilton RG: Hyperglycemic pseudohypoxia and diabetic complications. Diabetes 1993, 42:801-813.

8. Colwell GA: Inflammation and diabetic vascular complications. Diabetes Care 1999, 22:1927-1928.

9. Joussen AM, Poulaki V, Mitsiades N, Kirchhof B, Koizumi K, Dohmen S, Adamis AP: Nonsteroidal anti-inflammatory drugs prevent early diabetic retinopathy via TNF-alpha suppression. FASEB J 2002, 16:438-440.

10. van Hecke MV, Dekker JM, Nijpels G, Moll AC, Heine RJ, Bouter LM, Polak BC, Stehouwer CD: Inflammation and endothelial dysfunction are associated with retinopathy: the Hoorn Study. Diabetologia 2005, 48:1300-1306. 
11. Kern TS: Contributions of inflammatory processes to the development of the early stages of diabetic retinopathy. Exp Diabetes Res 2007, 2007:95103.

12. Barber AJ, Lieth E, Khin SA, Antonetti DA, Buchanan AG, Gardner TW: Neural apoptosis in the retina during experimental and human diabetes. Early onset and effect of insulin. J Clin Invest 1998, 102:783-791.

13. Barber AJ: A new view of diabetic retinopathy: a neurodegenerative disease of the eye. Prog Neuropsychopharmacol Biol Psychiatry 2003, 27:283-290.

14. Moore P, El-sherbeny A, Roon P, Schoenlein PV, Ganapathy V, Smith SB: Apoptotic cell death in the mouse retinal ganglion cell layer is induced in vivo by the excitatory amino acid homocysteine. Exp Eye Res 2001, 73:45-57.

15. Lieth E, Barber AJ, Xu B, Dice C, Ratz MJ, Tanase D, Strother JM: Glial reactivity and impaired glutamate metabolism in short-term experimental diabetic retinopathy. Penn State Retina Research Group. Diabetes 1998, 47:815-820.

16. Wu SZ, Bodles AM, Porter MM, Griffin WS, Basile AS, Barger SW: Induction of serine racemase expression and D-serine release from microglia by amyloid beta-peptide. J Neuroinflammation 2004, 1:2.

17. Wu SZ, Jiang S, Sims TJ, Barger SW: Schwann cells exhibit excitotoxicity consistent with release of NMDA receptor agonists. J Neurosci Res 2005, 79:638-643.

18. Inoue R, Hashimoto K, Harai T, Mori H: NMDA- and beta-amyloid1-42induced neurotoxicity is attenuated in serine racemase knock-out mice. J Neurosci 2008, 28:14486-14491.

19. Mustafa AK, Ahmad AS, Zeynalov E, Gazi SK, Sikka G, Ehmsen JT, Barrow RK, Coyle JT, Snyder SH, Dore S: Serine racemase deletion protects against cerebral ischemia and excitotoxicity. J Neurosci 30:1413-1416.

20. Stevens ER, Esguerra M, Kim PM, Newman EA, Snyder SH, Zahs KR, Miller RF: $D$-serine and serine racemase are present in the vertebrate retina and contribute to the physiological activation of NMDA receptors. Proc Natl Acad Sci USA 2003, 100:6789-6794.

21. Schell MJ, Molliver ME, Snyder SH: D-serine, an endogenous synaptic modulator: localization to astrocytes and glutamate-stimulated release. Proc Natl Acad Sci USA 1995, 92:3948-3952.

22. Wu S, Barger SW, Sims TJ: Schwann cell and epineural fibroblast expression of serine racemase. Brain Res 2004, 1020:161-166.

23. Hashimoto K, Fukushima T, Shimizu E, Komatsu N, Watanabe H, Shinoda N, Nakazato M, Kumakiri C, Okada S, Hasegawa H, et al: Decreased serum levels of D-serine in patients with schizophrenia: evidence in support of the N-methyl-D-aspartate receptor hypofunction hypothesis of schizophrenia. Arch Gen Psychiatry 2003, 60:572-576.

24. Heresco-Levy U, Javitt DC, Ebstein R, Vass A, Lichtenberg P, Bar G, Catinari S, Ermilov M: D-serine efficacy as add-on pharmacotherapy to risperidone and olanzapine for treatment-refractory schizophrenia. Biol Psychiatry 2005, 57:577-585.

25. Labrie V, Fukumura R, Rastogi A, Fick LJ, Wang W, Boutros PC, Kennedy JL, Semeralul MO, Lee FH, Baker GB, et al: Serine racemase is associated with schizophrenia susceptibility in humans and in a mouse model. Hum Mol Genet 2009, 18:3227-3243.

26. Sasabe J, Chiba T, Yamada M, Okamoto K, Nishimoto I, Matsuoka M, Aiso S: $\mathrm{D}$-serine is a key determinant of glutamate toxicity in amyotrophic lateral sclerosis. Embo J 2007, 26:4149-4159.

27. Ryu HJ, Kim JE, Yeo SI, Kim DS, Kwon OS, Choi SY, Kang TC: Potential roles of $D$-serine and serine racemase in experimental temporal lobe epilepsy. J Neurosci Res 88:2469-2482.

28. Foltyn VN, Zehl M, Dikopoltsev E, Jensen ON, Wolosker H: Phosphorylation of mouse serine racemase regulates D-serine synthesis. FEBS Lett 584:2937-2941.

29. Dumin E, Bendikov I, Foltyn VN, Misumi Y, Ikehara Y, Kartvelishvily E, Wolosker H: Modulation of D-serine levels via ubiquitin-dependent proteasomal degradation of serine racemase. J Biol Chem 2006, 281:20291-20302.

30. Wu S, Basile AS, Barger SW: Induction of serine racemase expression and D-serine release from microglia by secreted amyloid precursor protein (sAPP). Curr Alzheimer Res 2007, 4:243-251.

31. Wu S, Barger SW: Induction of serine racemase by inflammatory stimuli is dependent on AP-1. Ann N Y Acad Sci 2004, 1035:133-146.

32. Hashimoto A, Nishikawa T, Oka T, Takahashi K, Hayashi T: Determination of free amino acid enantiomers in rat brain and serum by high- performance liquid chromatography after derivatization with $\mathrm{N}$-tert.butyloxycarbonyl-L-cysteine and o-phthaldialdehyde. J Chromatogr 1992, 582:41-48.

33. Martin PM, Roon P, Van Ells TK, Ganapathy V, Smith SB: Death of retinal neurons in streptozotocin-induced diabetic mice. Invest Ophthalmol Vis Sci 2004, 45:3330-3336

34. Kusari J, Zhou S, Padillo E, Clarke KG, Gil DW: Effect of memantine on neuroretinal function and retinal vascular changes of streptozotocininduced diabetic rats. Invest Ophthalmol Vis Sci 2007, 48:5152-5159.

35. Kaneto H, Xu G, Fujii N, Kim S, Bonner-Weir S, Weir GC: Involvement of cJun $\mathrm{N}$-terminal kinase in oxidative stress-mediated suppression of insulin gene expression. J Biol Chem 2002, 277:30010-30018.

36. Kawamori D, Kajimoto $Y$, Kaneto $H$, Umayahara $Y$, Fujitani $Y$, Miyatsuka T, Watada $H$, Leibiger IB, Yamasaki Y, Hori M: Oxidative stress induces nucleo-cytoplasmic translocation of pancreatic transcription factor PDX1 through activation of c-Jun $\mathrm{NH}(2)$-terminal kinase. Diabetes 2003, 52:2896-2904.

37. Poulaki V, Joussen AM, Mitsiades N, Mitsiades CS, lliaki EF, Adamis AP: Insulin-like growth factor-I plays a pathogenetic role in diabetic retinopathy. Am J Pathol 2004, 165:457-469.

38. Dun Y, Duplantier J, Roon P, Martin PM, Ganapathy V, Smith SB: Serine racemase expression and $D$-serine content are developmentally regulated in neuronal ganglion cells of the retina. J Neurochem 2008, 104:970-978

39. Bode AM, Dong Z: The functional contrariety of JNK. Mol Carcinog 2007, 46:591-598.

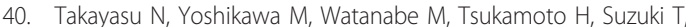
Kobayashi H, Noda S: The serine racemase mRNA is expressed in both neurons and glial cells of the rat retina. Arch Histol Cytol 2008, 71:123-129.

41. Hama Y, Katsuki H, Tochikawa Y, Suminaka C, Kume T, Akaike A: Contribution of endogenous glycine site NMDA agonists to excitotoxic retinal damage in vivo. Neurosci Res 2006, 56:279-285.

42. Wallow $\mathrm{H}$ : Posterior and anterior permeability defects? Morphologic observations on streptozotocin-treated rats. Invest Ophthalmol Vis Sci 1983, 24:1259-1268.

43. Antonetti DA, Barber AJ, Khin S, Lieth E, Tarbell JM, Gardner TW: Vascular permeability in experimental diabetes is associated with reduced endothelial occludin content: vascular endothelial growth factor decreases occludin in retinal endothelial cells. Penn State Retina Research Group. Diabetes 1998, 47:1953-1959.

44. Anthony IC, Crawford DH, Bell JE: B lymphocytes in the normal brain: contrasts with HIV-associated lymphoid infiltrates and lymphomas. Brain 2003, 126:1058-1067

45. Yan SD, Yan SF, Chen X, Fu J, Chen M, Kuppusamy P, Smith MA, Perry G, Godman GC, Nawroth $P$, et al: Non-enzymatically glycated tau in Alzheimer's disease induces neuronal oxidant stress resulting in cytokine gene expression and release of amyloid beta-peptide. Nat Med 1995, 1:693-699.

46. Choei H, Sasaki N, Takeuchi M, Yoshida T, Ukai W, Yamagishi S, Kikuchi S, Saito T: Glyceraldehyde-derived advanced glycation end products in Alzheimer's disease. Acta Neuropathol 2004, 108:189-193.

47. Stoll G, Jander S: The role of microglia and macrophages in the pathophysiology of the CNS. Prog Neurobiol 1999, 58:233-247.

doi:10.1186/1742-2094-8-119

Cite this article as: Jiang et al:: Overexpression of serine racemase in retina and overproduction of D-serine in eyes of streptozotocin-induced diabetic retinopathy. Journal of Neuroinflammation 2011 8:119. 